\title{
Partial Response to Platinum Doublets in Refractory EGFR-Positive Non-Small Cell Lung Cancer Patients after RRx-001: Evidence of Episensitization
}

\author{
Corey A. Carter ${ }^{\mathrm{a}} \quad$ Bryan T. Oronsky $^{\mathrm{b}}$ Scott Z. Caroen $^{\mathrm{b}} \quad$ Jan J. Scicinski ${ }^{\mathrm{b}}$ \\ Pedro Cabrales $^{c}$ Tony Reid $^{d}$ Aiste Degesys $^{a} \quad$ John Jenkins $^{a}$ \\ Christina Brzezniak ${ }^{a}$ \\ ${ }^{a}$ Walter Reed National Military Medical Center, Bethesda, Md., \\ ${ }^{b}$ EpicentRx, Inc., Mountain View, Calif., ' Department of Bioengineering, University of \\ California, and ${ }^{\mathrm{d}}$ Moores Cancer Center, University of California and San Diego, \\ La Jolla, Calif., USA
}

\section{Key Words}

Partial response $\cdot$ Platinum doublets $\cdot$ Refractory EGFR $\cdot$ Non-small cell lung cancer $\cdot$ RRx-001

\begin{abstract}
RRx-001, an experimental systemically non-toxic epi-immunotherapeutic agent, which potentiates the resensitization of resistant cancer cells to formerly effective therapies, is under active investigation in several clinical trials that are based on sequential or concomitant rechallenge to resistant first- or second-line regimens. One of these trials is designated TRIPLE THREAT (NCT02489903), because it explores the conditioning or priming effect of RRx-001 on three tumor types - non-small cell lung cancer (NSCLC), small cell lung cancer and highgrade neuroendocrine tumors - prior to re-administration of platinum doublets. In follow-up to a recent case study, which describes early monotherapeutic benefit with RRx-001 in a refractory EGFR-mutated NSCLC tumor, we present subsequent evidence of a radiological partial response to reintroduced platinum doublets after RRx-001. For the $50 \%$ of patients with EGFR-mutated NSCLC who progress on EGFR-tyrosine kinase inhibitors (without evidence of a T790M mutations) as well as platinum doublets and pemetrexed/taxane, no other clinically established treatment options exist. A retrial of these therapies in EGFR-positive NSCLC pa-
\end{abstract}

\section{KARGER}

Jan J. Scicinski

EpicentRx, Inc

800 W El Camino Real, Suite 180

Mountain View, CA 94040 (USA)

E-Mail jscicinski@epicentrx.com 
Carter et al.: Partial Response to Platinum Doublets in Refractory EGFR-Positive Non-Small Cell Lung Cancer Patients after RRx-001: Evidence of Episensitization

tients via priming with epigenetic agents such as RRx-001 constitutes a strategy to 'episensitize' tumors (i.e. reverse resistance by epigenetic means) and to extend overall survival.

(C) 2016 The Author(s)

Published by S. Karger AG, Basel

\section{Introduction}

Therapy selection guidelines for EGFR-mutated non-small cell lung cancer (NSCLC) patients are as follows:

- $\quad$ First line: tyrosine kinase inhibitors (TKIs) for EGFR-sensitizing mutations (exons 18,19, and 21), including erlotinib [1] and afatinib [2], approved for use in the United States, as well as gefitinib [3], which has recently received reapproval for use in the United States.

- $\quad$ Second-line TKIs: upon progression, it is recommended to biopsy the site of progression to determine if a new resistant mutation has developed (exon 20 mutation) T790M. If this new resistant mutation exists, patients are now offered osimertinib [4], which has recently been approved in the United States.

- $\quad$ Second line if the patient has no T790M mutation: 4-6 cycles of platinum-based chemotherapy such as platinum/pemetrexed [5], after which patients are observed for evidence of disease progression [6]. Third-line therapy generally follows progression. Elderly patients with significant comorbidities appear to tolerate the platinum doublets, carboplatin and nanoparticle albumin-bound paclitaxel with a reduced toxicity profile as an option [7].

- $\quad$ Third line: single agent docetaxel or pemetrexed (whichever has not been used so far). After disease progression, in the absence of clinical deterioration, patients may be referred for clinical trials (fig. 1).

While the successful reintroduction to TKIs or standard chemotherapy after progression in EGFR-mutated NSCLC patients has been documented in the literature [8], a rechallenge strategy is generally contraindicated on the assumption that re-exposure will yield toxicity rather than benefit due to the stability of the chemo-resistant phenotype $[9,10]$. An emerging paradigm called episensitization, which attempts to epigenetically condition or 'prime' the tumor to re-respond to refractory chemotherapy, challenges the long-held practice of permanently discontinuing a particular treatment at the time of disease progression [11]. Hypothetically, like a therapeutic 'do-over', episensitized patients restart prior effective regimens each time from a state of scratch rather than from the disadvantage of a progressively entrenched non-responsiveness, potentially leading to the 'chronification' of a once fatal disease. Accordingly, in a phase II clinical trial called TRIPLE THREAT (NCT02489903), patients with three tumor types - NSCLC, small cell lung cancer and high-grade neuroendocrine tumors or carcinomas (hence the name TRIPLE THREAT) - receive the experimental systemically non-toxic immuno-epigenetic agent, RRx-001 [12-14], until RECIST v. 1.1defined progression, followed by the reintroduction of platinum doublets. Figure 2 shows a schematic description of the TRIPLE THREAT trial.

In the present report, a follow-up to a recently published case report in this journal [15], which details dramatic RRx-001-induced intratumoral necrosis and immune infiltration in an EGFR-mutated NSCLC patient, evidence of subsequent episensitization to platinum doublets in the form of a partial response is described. 
Carter et al.: Partial Response to Platinum Doublets in Refractory EGFR-Positive Non-Small Cell Lung Cancer Patients after RRx-001: Evidence of Episensitization

\section{Case}

A 49-year-old never-smoking male with EGFR-sensitizing positive mutated NSCLC and clear failure to erlotinib as well as carboplatin and pemetrexed received 5 weekly doses of intravenous RRx-001 (4 mg) with simultaneous infusions of autologous blood per the TRIPLE THREAT (NCT02489903) protocol. In the 5th week of treatment, he was reimaged with PET/CT due to progressively worsening abdominal pain, which demonstrated a dramatically enlarged necrotic mass with a thin capsule of apparently viable tumor (fig. 3).

Despite this clearly beneficial response to treatment, tumor enlargement mandated discontinuation of RRx-001 per RECIST v.1.1 criteria for progression, and the patient was restarted on platinum doublets (cisplatin $75 \mathrm{mg} / \mathrm{m}^{2}$ i.v. + nab-paclitaxel $100 \mathrm{mg} / \mathrm{m}^{2}$ i.v.). After only one cycle, the patient, coping poorly with the persistent abdominal pain, nausea, cachexia, and fatigue, due to the size of the mass, requested an extended break from treatment to spend time with his wife and small children. Almost 3 weeks later, the investigators were pleasantly surprised when the patient called to report that his energy, appetite, productivity, and weight had recovered in the absence of treatment to the point that for the first time in recent memory he was looking forward to the holidays.

On December 22, 2015, the patient was reimaged with PET/CT, which demonstrated a partial response (30\% decrease in sum from baseline) as well as a metabolic response relative to the previous PET/CT on November 27, 2015. These images are shown (fig. 3).

\section{Discussion}

This follow-up case report documents an unprecedented clinical and radiological partial response of a patient with platinum and TKI-refractory EGFR-mutated NSCLC with no further treatment options, having progressed through multiple lines of targeted and systemic chemotherapy, including a previous clinical trial with TH-4000 (tarloxotinib), a pro-drug of a TKI [16], which did not benefit the patient. His response was all the more remarkable because it occurred after only one dose of protocol-mandated rechallenge with platinum doublets, demonstrating a potential epigenetic resensitization i.e. 'episensitization' due to RRx001 pretreatment or priming.

Patients with platinum and TKI-refractory EGFR-mutated NSCLC have an average survival measured in months only [17]. Moreover, from the moment that treatment starts in first line, the clock is winding down along with viable therapeutic options, and it is only a question of time when - rather than if - resistance and treatment failure will occur. Since the accumulation of treatment-induced epigenetic changes are in theory reversible [18], unlike genetic mutations, the episensitization tabula rasa has the potential to wipe the resistance slate clean and rewind the ticking doomsday clock all the way back to first or second line. The result, hopefully, is improved functional status and overall survival, translating to more quality time, which is what occurred in the case of this fortunate patient.

\section{Statement of Ethics}

The case report was conducted according to the Declaration of Helsinki principles. The patient gave written informed consent. 


\section{Case Reports in Oncology}

\begin{tabular}{|c|c|}
\hline Case Rep Oncol 2016;9:62 & \\
\hline DOI: $10.1159 / 000443725$ & $\begin{array}{l}\text { (C) } 2016 \text { The Author(s). Published by S. Karger AG, Basel } \\
\text { www.karger.com/cro }\end{array}$ \\
\hline
\end{tabular}

Carter et al.: Partial Response to Platinum Doublets in Refractory EGFR-Positive Non-Small Cell Lung Cancer Patients after RRx-001: Evidence of Episensitization

\section{Disclosure Statement}

B.T.O., J.J.S. and S.Z.C. are employees of EpicentRx, Inc. EpicentRx, Inc. provided funding for the study.

\section{References}

1 Rosell R, Carcereny E, Gervais R, et al: Erlotinib versus standard chemotherapy as first-line treatment for European patients with advanced EGFR mutation-positive non-small-cell lung cancer (EURTAC): a multicentre, open-label, randomised phase 3 trial. Lancet Oncol 2012;13:239-246.

-2 Wu YL, Zhou C, Hu CP, et al: Afatinib versus cisplatin plus gemcitabine for first-line treatment of Asian patients with advanced non-small-cell lung cancer harbouring EGFR mutations (LUX-Lung 6): an open-label, randomised phase 3 trial. Lancet Oncol 2014;15:213-222.

-3 Mok TS, Wu YL, Thongprasert S, et al: Gefitinib or carboplatin-paclitaxel in pulmonary adenocarcinoma. N Engl J Med 2009;361:947-957.

4 http://www.fda.gov/NewsEvents/Newsroom/PressAnnouncements/ucm472525.htm (accessed December 29, 2015).

5 Schiller JH, Harrington D, Belani CP, Langer C, Sandler A, Krook J, Zhu J, Johnson DH, and Eastern Cooperative Oncology Group: Comparison of four chemotherapy regimens for advanced non-small-cell lung cancer. N Engl J Med 2002;346:92-98.

-6 Hirsh V: Systemic therapies in metastatic non-small-cell lung cancer with emphasis on targeted therapies: the rational approach. Curr Oncol 2010;17:13-23.

7 Socinski MA, Bondarenko I, Karaseva NA, et al: Weekly nab-paclitaxel in combination with carboplatin versus solvent-based paclitaxel plus carboplatin as first-line therapy in patients with advanced non-smallcell lung cancer: final results of a phase III trial. J Clin Oncol 2012;30:2055-2062.

-8 Zhao ZR, Li W, Long H: Readministration of EGFR tyrosine kinase inhibitor in non-small cell lung cancer patients after initial failure, what affects its efficacy? Sci Rep 2014;4:5996.

-9 Oronsky B, Carter CA, Reid TR, Scicinski J, Oronsky A, Lybeck M, Caroen S, Stirn M, Oronsky N, Langecker P: Confirmatory trials in the evaluation of anticancer medicinal products in Man-PFS2: a measure of therapeutic action-at-a-distance. Neoplasia 2015;17:716-722.

10 Oronsky B, Oronsky N, Scicinski J, Fanger G, Lybeck M, Reid T: Rewriting the epigenetic code for tumor resensitization: a review. Transl Oncol 2014;7:626-631.

Oronsky BT, Oronsky AL, Lybeck M, et al: Episensitization: defying time's arrow. Front Oncol 2015;5:134. Zhao H, Ning S, Scicinski J, Oronsky B, Knox SJ, Peehl DM: Epigenetic effects of RRx-001: a possible unifying mechanism of anticancer activity. Oncotarget 2015;6:43172-43181.

13 Reid T, Dad S, Korn R, Oronsky B, Knox S, Scicinski J: Two case reports of resensitization to previous chemotherapy with the novel hypoxia-activated hypomethylating anticancer agent RRx-001 in metastatic colorectal cancer patients. Case Rep Oncol 2014;7:79-85.

14 Reid T, Oronsky B, Scicinski J, et al: Safety and activity of RRx-001 in patients with advanced cancer: a firstin-human, open-label, dose-escalation phase 1 study. Lancet Oncol 2015;16:1133-1142.

15 Brzezniak C, Schmitz BA, Peterson PG, Degesys A, Oronsky B, Scicinski JJ, Caroen SZ, Carter CA: RRx-001induced tumor necrosis and immune cell infiltration in an EGFR mutation-positive NSCLC with resistance to EGFR tyrosine kinase inhibitors: a case report. Case Rep Oncol 2016;9:45-50.

-16 Shepherd FA, Rodrigues Pereira J, Ciuleanu T, et al: Erlotinib in previously treated non-small-cell lung cancer. N Engl J Med 2005;353:123-132.

17 Nguyen KS, Neal JW: First-line treatment of EGFR-mutant non-small-cell lung cancer: the role of erlotinib and other tyrosine kinase inhibitors. Biologics 2012;6:337-345.

$\longrightarrow 18$ Sharma S, Kelly TK, Jones PA: Epigenetics in cancer. Carcinogenesis 2010;31:27-36. 


\section{EGFR Mutation +}
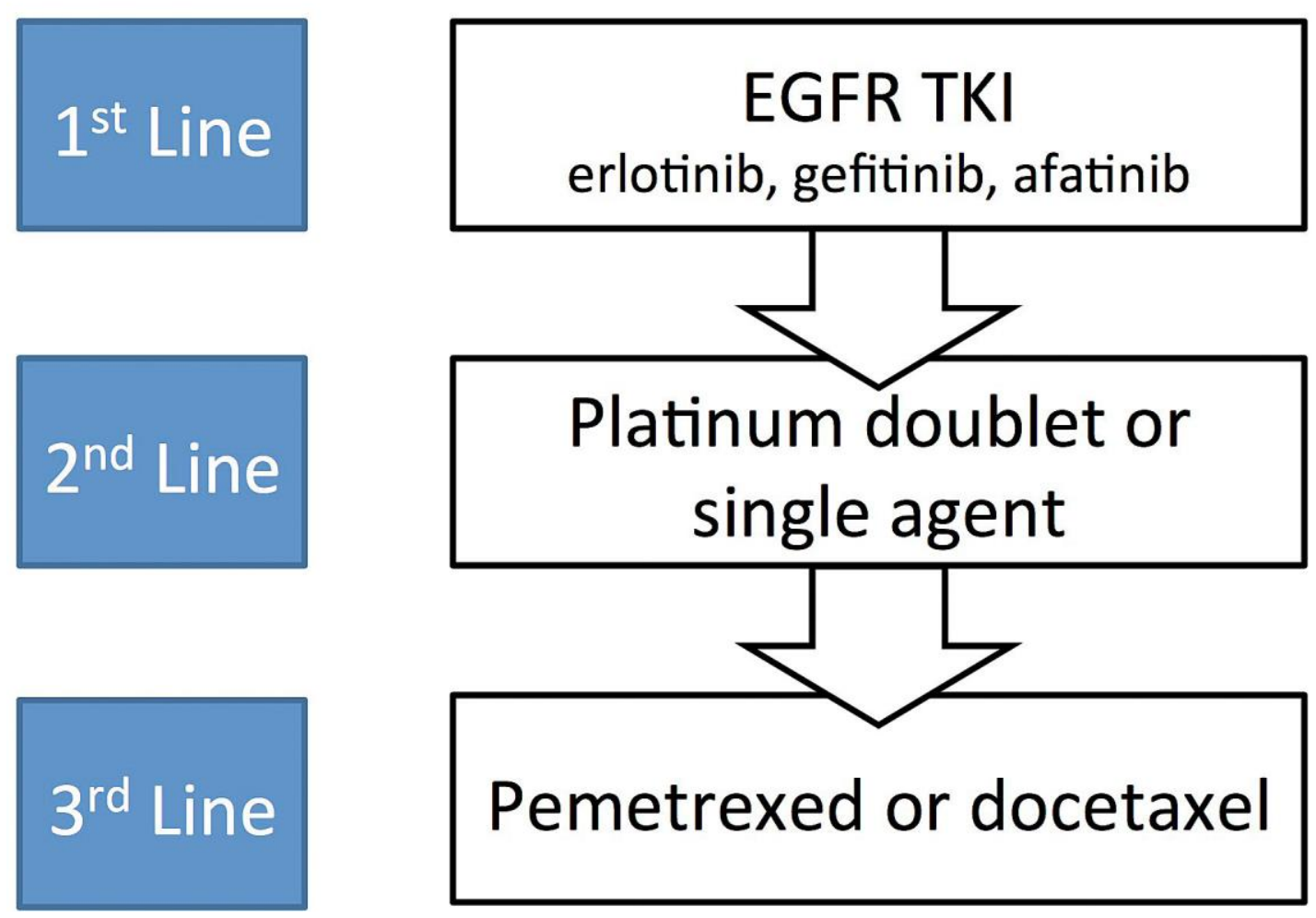

Fig. 1. NSCLC EGFR mutation-positive treatment algorithm. 


\section{Case Reports in Oncology}

\begin{tabular}{l|l}
\hline Case Rep Oncol 2016;9:62-67 \\
\hline DOI: 10.1159/000443725 & $\begin{array}{l}\text { (c) 2016 The Author(s). Published by S. Karger AG, Basel } \\
\text { www.karger.com/cro }\end{array}$ \\
\hline
\end{tabular}

Carter et al.: Partial Response to Platinum Doublets in Refractory EGFR-Positive Non-Small Cell Lung Cancer Patients after RRx-001: Evidence of Episensitization

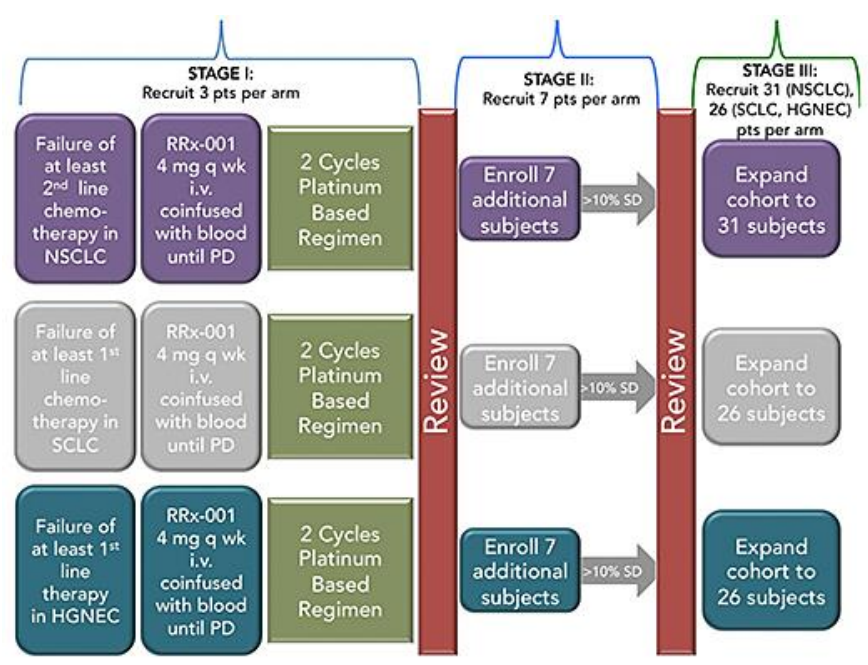

Fig. 2. Schema of the TRIPLE THREAT clinical trial. SCLC = Small cell lung cancer; HGNEC = high-grade neuroendocrine carcinoma; $\mathrm{PD}=$ progressive disease; $\mathrm{SD}=$ stable disease.
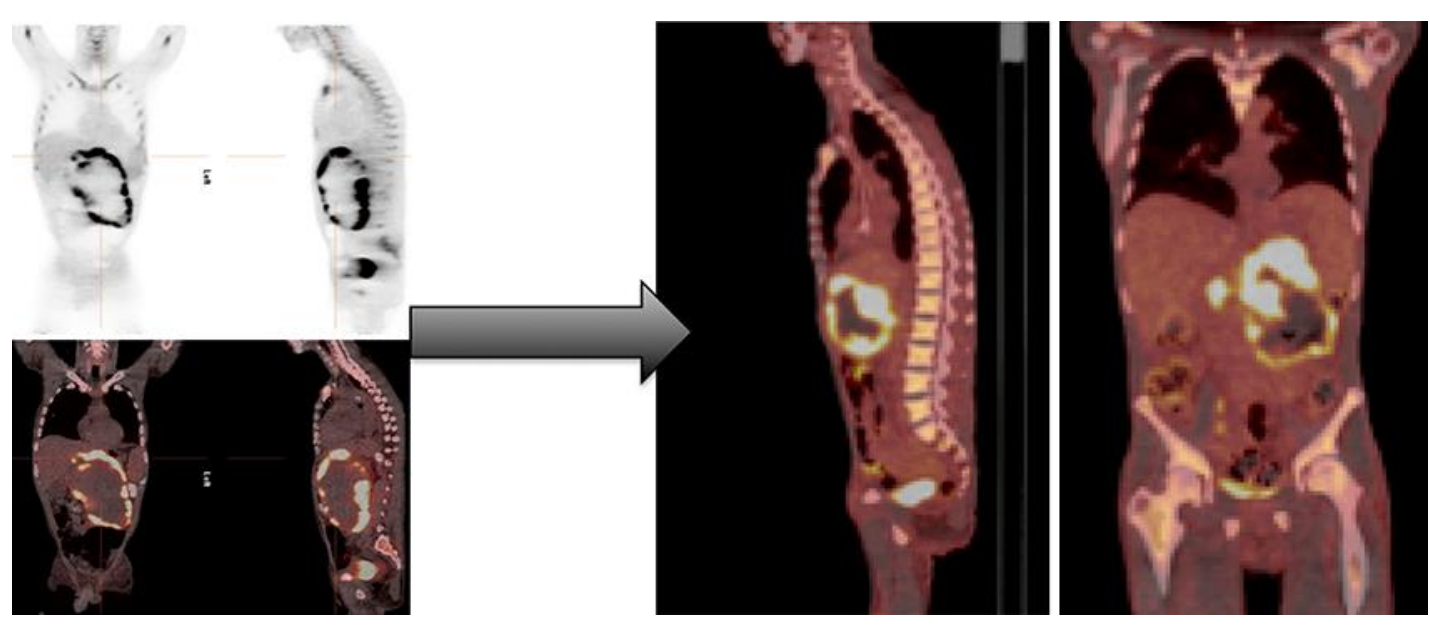

Fig. 3. On the left, PET/CT from November 27, 2015 demonstrating RRx-001-induced central infarction of an abdominal metastasis. On the right, PET/CT from December 22, 2015 showing dramatic shrinkage of the lesion after one dose of cisplatin and pemetrexed, indicative of episensitization. The high FDG uptake in the discontinuous rind of the tumor may be secondary to invasion by inflammatory cells. Note the FDGavid myocardium just above the tumor on the left. 